\title{
Применение вихревых газодинамических охладителей в техноло- гиях извлечения редких газов
}

\author{
В. Л. Бондаренко ${ }^{1}$, Ю. М. Симоненко ${ }^{2}$, Л. Н. Цветковская ${ }^{3}$, Д. П. Тиико \\ 1 Московский государственный технический университет им. Н.Э. Баумана, ул. 2-ая Бауманская, 5, Москва, \\ 107005, РФ \\ 2,3 Одесская национальная академия пищевых технологий, ул. Канатная, 112, Одесса, 65039, Украина \\ ${ }^{4}$ ООО «Криоин Инжиниринг», Таможенная площадь, 1 А, Одесса, 65026, Украина \\ $\triangle$ e-mail: dtishko@cryoin.com ORCID: ${ }^{1}$ http://orcid.org/0000-0003-1562-7255; ${ }^{2}$ http://orcid.org/0000-0002-7827-0591; \\ ${ }^{3}$ https://orcid.org/0000-0002-3956-583X $;{ }^{4}$ http://orcid.org/0000-0002-9598-6292;
}

Вихревые трубы по эффективности уступают детандерам, но обладают рядом неоспоримых преимущчеств, таких как компактность, надежность, многофункциональность. Несмотря на эти достоинства, существует совсем немного примеров эффективного применения вихревых аппаратов в криогенике. В работе рассмотрены проблемы, сопутствующие созданию вихревых охладителей, предназначенных для установок получения неона и гелия. Переход к низким температурам всегда сопровождается миниатюризацией газодинамических аппаратов. В то же время больиинство рекомендаций по проектированию вихревой техники относится к высокорасходным устройствам, которые питаются сжатым воздухом при температуре окружающей среды. По этой причине известные геометрические соотношения не всегда применимы при создании криогенных вихревых установок с малыми диаметрами камеры энергоразделения. Экспериментальным путем изучено влияние масштабного фактора в интервале диаметров меньше 10 мм. Показаны преимущества ступенчатого включения низкотемпературных вихревых труб в схемах сепараторов редких газов. Обосновано использование технологического перепада давлений для питания вихревых криогенераторов. При этом работа газодинамических охладителей не требует дополнительных затрат энергии, поскольку в них срабатывается давление сжатого газа, которое ранее бесполезно редуцировалось.

Ключевье слова: Криогенная техника; Редкие газы, Вихревая труба; Масштабный фактор.

\section{Використання вихрових газодинамічних охолоджувачів в технологіях вилучення рідкісних газів}

\author{
В. Л. Бондаренко ${ }^{1}$ Ю. М. Симоненко ${ }^{2}$, Л. Н. Цветковская ${ }^{3}$, Д. П. Тишко \\ ${ }_{1}^{1}$ Московський державний технічний університет ім. Н.Е. Баумана, вул. 2-а Бауманьска, 5, Москва, 107005, РФ \\ 2,3 Одеська національна академія харчових технологій, вул. Канатна, 112, Одесса, 65039, Україна \\ ${ }^{4}$ ООО «Кріоін Інжиніринг», Митна площа, 1 А, Одесса, 65026, Україна
}

За ефективністю вихрові труби поступаються детандерам, але мають ряд незаперечних переваг, таких як компактність, надійність, багатофункиіональність. Незважсаючи на иі переваги, існує зовсім небагато прикладів ефективного застосування вихрових апаратів в кріогенній техніці. В роботі розглянуті проблеми, супутні створенню вихрових охолоджувачів, призначених для установок отримання неону та гелію. Перехід до низьких температур завжди супроводжується мініатюризацією газодинамічних апаратів. У той же час, більшість рекомендаиій з проектування вихрової техніки відноситься до високовитратних пристроїв, котрі використовують стиснене повітря при температурі навколишнього середовища. 3 ичієї причини відомі геометричні співвідношення не завжди застосовуються при створенні кріогенних вихрових установок з малими діаметрами камери енергоподілу. Експериментальним шляхом було з'ясовано вплив масштабного фактору в інтервалі діаметрів камері енергоподілу менше 10 мм. Показані переваги ступеневого включення низькотемпературних вихрових труб до схем сепараторів рідких газів. Обтрунтовано використання технологічного перепаду тисків для харчування вихрових кріогенераторів. При цьвому робота газодинамічних охолоджувачів не вимагає додаткових витрат енергї, оскільки в них спраџьовується тиск стисненого газу, яке раніше марно редуцњюювалось

Ключові слова: Кріогенна техніка; Рідкісні гази, Вихрова труба; Масштабний фактор.

(C) The Author(s) 2018. This article is an open access publication

This work is licensed under the Creative Commons Attribution 4.0 International License (CC BY) http://creativecommons.org/licenses/by/4.0/

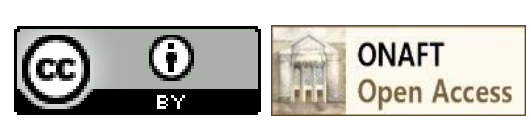




\section{Введение}

Первая в СССР кандидатская диссертация по исследованию вихревой трубы была подготовлена в Одесском институте пищевой и холодильной промышленности В. П. Алексеевым под научным руководством В. С. Мартыновского [1]. В последующие годы исследования газодинамических охладителей были продолжены в Лаборатории вихревых генераторов холода при Проблемной лаборатории ОТИХП, которой руководил А. И. Азаров [2]. В 70-е - 80-е годы были созданы десятки промышленных аппаратов, которые были востребованы в авиации и космонавтике, охлаждали продукты питания и атмосферу в кабинах электровозов и грузовиков, работали в горячих цехах и в глубоких шахтах. Одесские вихревые трубы (Вихревые трубы, разработанные в Одессе) использовались в машиностроении, судоремонте, медицине, электронике [3].

Безмашинные аппараты занимают особое место в числе охладителей, использующих энергию сжатого газа. Они уступают детандерам по эффективности, но обладают совокупностью неоспоримых эксплуатационных и конструктивных преимуществ. Среди них - высокая надежность, многофункциональность, безинерционность, компактность, простота изготовления. Однако, использование газодинамических устройств при низких температурах сопряжено с рядом конструкционных и технологических проблем. Создание промышленных вихревых аппаратов для криогеники предопределило проведение дополнительных исследований и разработку новых технологических приемов изготовления элементов проточной части маломасштабных газодинамических устройств.

\section{1. Устройство и принцип работы вихревых охлади- телей}

В вихревую трубу (рис. 1) сжатый газ подается через тангенциальный сопловой ввод 1 в камеру энергоразделения 3. Расширяясь, газ образует высокоскоростной поток, и разделяется на холодную (с температурой $T \mathrm{x}<T \mathrm{c})$ и нагретую (с температурой $T \Gamma>T \mathrm{c})$ составляющие. Охлажденный поток формируется в осевой зоне камеры 3 и выходит из вихревой трубы через отверстие диафрагмы 2, расположенное вблизи соплового сечения Б-Б. Нагретый поток образуется в периферийной зоне камеры и движется вдоль ее стенки в направлении, обратном направлению движения охлажденного потока. С целью турбулизации вращающегося потока на торце камеры энергоразделения устанавливают крестовину 4. Горячий газ выходит из вихревой трубы через регулирующий вентиль 5. При изменении степени открытия вентиля варьируются расходы и температуры охлажденного и нагретого потоков. В случае достаточно большой площади проходного сечения вентиля 5 вихревая труба может перейти в режим эжектора, всасывая внутрь камеры окружающий воздух через отверстие диафрагмы $(G \Gamma>G c)$. Полное закрытие вентиля приводит к выходу через диафрагму всего газа, поступающего в вихревую трубу $(G \mathrm{c}=G \mathrm{x}, G \Gamma=0)$, практически без изменения его температуры. Для обеспечения перепада температур в таком режиме вихревая труба нуждается в отводе тепла через стенки камеры. С этой целью используют охлаждающую рубашку или эффективное оребрение [4].

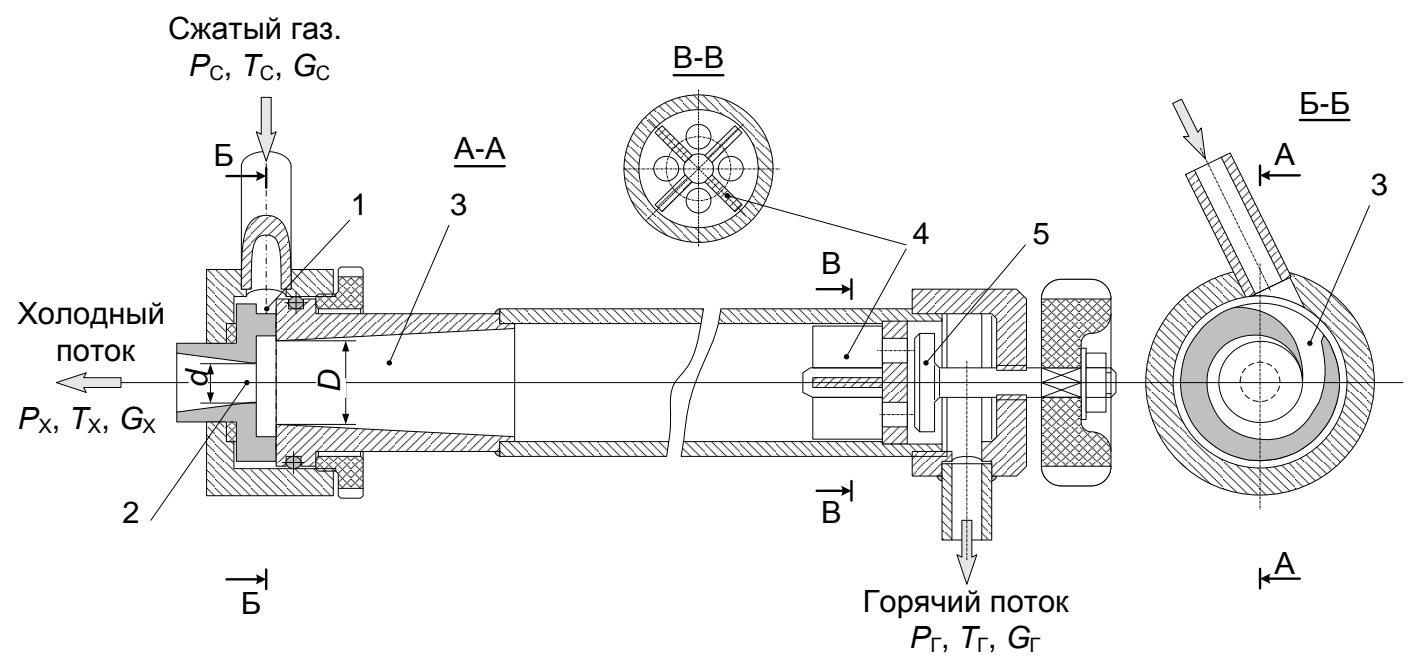

1 - спиральный сопловой ввод; 2 - диафрагма; 3 - камера энергоразделения; 4 - крестовина; 5 - регулирующий вентиль

Рисунок 1 - Упрощенная конструкция крупномасштабной вихревой трубы

Механизм температурного разделения в вихревых камерах сопровождается перераспределением энергии между вращающимися слоями газа. Первые исследования структуры закрученного потока показали, что характер радиального распределения окружной скорости в приосевой и периферийной зонах вихря неодинаков [5]. На рисунке 2-а показано изменение окружной скорости по радиусу вихревой трубы для сечений, расположенных на различных расстояниях от плоскости диафрагмы. В периферийной области $(R>0,5 d)$ изме- 
нение окружной скорости $v_{\tau}$ подчиняется закону потенциального течения, при котором скорость увеличивается в направлении от стенки к оси (рисунок 2-б):

$$
v_{\tau} \cdot R=\text { const }
$$

где $R$ - радиус, [м].

В центральной части $(R<0,5 d)$ окружная скорость $v_{\tau}$ растет в обратном направлении - от оси к стенке камеры пропорционально радиусу $R$. Такой закон изменения скорости характерен для вращения частей твердого тела с постоянной угловой скоростью (рисунок 2-в):

$$
\omega=\frac{v_{\tau}}{R}=\text { const }
$$

По мере движения газа вдоль камеры энергоразделения (рис. 1 и 2-а) окружная скорость и радиальный градиент статического давления уменьшаются. Постепенно свободный вихрь начинает распространяться к оси, передавая часть кинетической энергии вращения осевому потоку. В соответствии с гипотезой А. П. Меркулова в процессе перехода газа в приосевую область происходит его интенсивная турбулизация [6]. Возникший обратный приосевой поток при движении закручивается все более интенсивным свободным вихрем. В ходе этого процесса кроме передачи кинетической энергии вращения, происходи и интенсивный теплообмен, отличающийся высоким градиентом статического давления. В сущности, элементы газовой среды совершают холодильные циклы, передавая тепло в периферийные слои, а источником механической энергии этих циклов являются турбулентные пульсации давления.

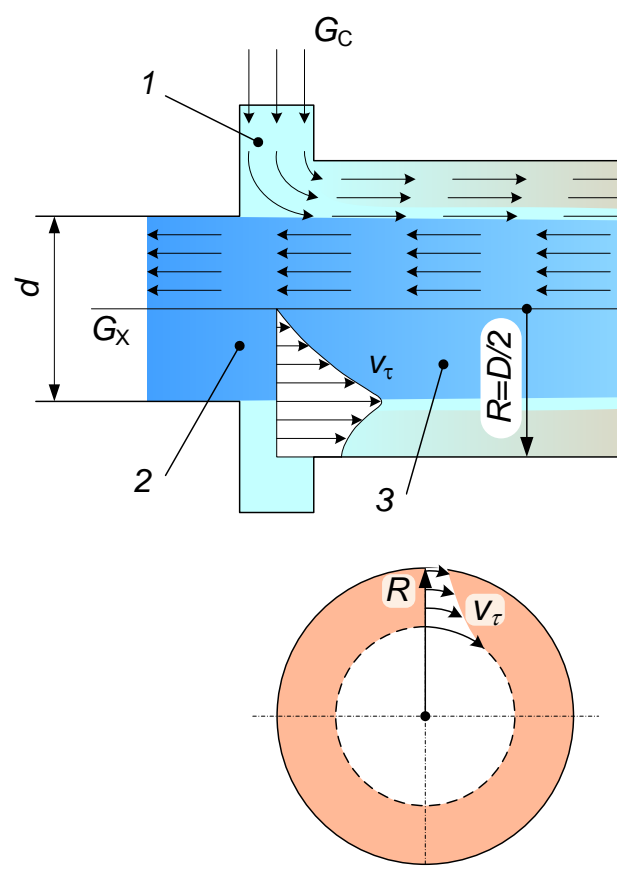

б) a)
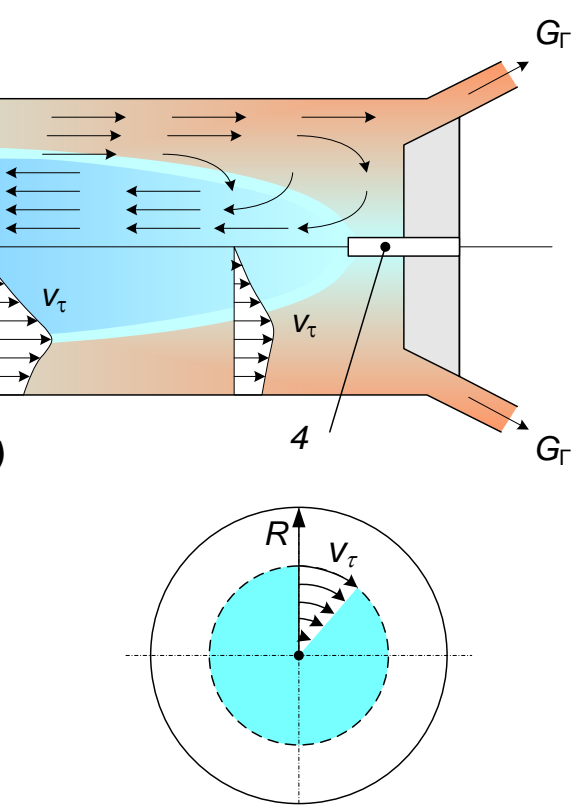

в)

Рисунок 2 - Характер изменение окружной скорости в различных сечениях вихревой трубы. (Обозначения соответствуют рис. 1)

Важнейшими эксплуатационными характеристиками вихревых охладителей являются:

относительная доля холодного потока

$$
\mu=\frac{G_{X}}{G_{\mathrm{C}}}
$$

где $G_{\mathrm{C}}$ и $G_{\mathrm{X}}-$ массовый расход сжатого и холодного потоков соответственно, [кг/ч]

и отношение давлений

$$
\varepsilon=\frac{P_{\mathrm{C}}}{P_{\mathrm{X}}}
$$

где $P_{\mathrm{C}}$ и $P_{\mathrm{X}}-$ давления сжатого и холодного потоков соответственно, [Па].

Холодный поток, выходящий из вихревой трубы через отверстие диафрагмы, должен иметь минимальную кинетическую энергию. При таком условии он будет выходить с наиболее низкой температурой во всем интервале доли холодного потока $\mu$.

\section{2. Основные геометрические размеры вихревой тру- бы}

Первые экспериментальные исследования циклонных газодинамических аппаратов показали, что оптимальные эксплуатационные параметры зависят не от абсолютных размеров отдельных элементов, а определяются их отношением к диаметру вихревой камеры $D$. При этом базовой конструктивной характеристикой для данного типа газодинамических аппаратов является сечение соплового ввода $F_{\mathrm{C}}$. Увеличение $F_{\mathrm{C}}$ при неизменном диаметре камеры энергоразделения увеличивает нагрузку на вихревую трубу и приводит к повышению гидравлического сопротивления диафрагмы холодного потока. Это, в свою очередь снижает реальный 
перепад давлений, который срабатывается в сопловом вводе, что приводит к снижению получаемого эффекта охлаждения $\Delta T_{\mathrm{X}}=T_{\mathrm{C}}-T_{\mathrm{X}}$. Обычно отношение сечения сопла к сечению вихревой камеры принимают в пределах

$$
\sigma=\frac{F_{\mathrm{C}}}{F_{\mathrm{D}}}=\frac{F_{\mathrm{C}}}{0,785 D^{2}}=0,085 \ldots 0,1,
$$

где $D$ - начальный диаметр камеры энергоразделения [м], $F_{\mathrm{C}}$ - сечение соплового ввода $\left[\mathrm{M}^{2}\right]$.

Для заданных параметров газа на входе $\left(P_{\mathrm{C}}\right.$ и $\left.T_{\mathrm{C}}\right)$, существует вполне определенная взаимосвязь между сечением сопла $F_{\mathrm{C}}$ и массовым расходом $G_{\mathrm{C}}$ [кг/с], [8]. В вихревых трубах, работающих в технологических циклах получения редких газов обычно имеют место закритические режимы истечения. Они обусловлены значительными располагаемыми перепадами давлений. При истечения идеального газа критическое отношение давлений $\varepsilon_{C}$ определяется показателем адиабаты $k$.

$$
\varepsilon_{\mathrm{C}}=\frac{P_{\mathrm{C}}}{P_{\mathrm{X}}}=\left(\frac{k+1}{2}\right)^{\frac{k}{k-1}},
$$

где $P_{\mathrm{C}}$ и $P_{\mathrm{X}}-$ давления сжатого и холодного потоков соответственно, [Па].

Величина $k$ для инертных газов (He, $\mathrm{Ne}, \mathrm{Ar}, \mathrm{Kr}$ и $\mathrm{Xe}$ ) находится в узком интервале $1,67 \pm 0,01$. В таком случае, в соответствии с формулой (6), $\varepsilon_{\mathrm{C}}=2,05 \ldots 2,06$. Отношения давлений, характерные для технологий получения редких газов, в несколько раз превышают критический отношение давлений. В этом случае давление холодного потока $P_{\mathrm{X}}$ не оказывает влияния на условия истечения и существует вполне определенная взаимосвязь между сечением сопла $F_{\mathrm{C}}$ и массовым расходом сжатого газа $G_{\mathrm{C}},[\kappa г / \mathrm{c}]$,

$$
F_{C}=\frac{G_{C} \cdot \sqrt{R^{*} \cdot T_{C}}}{P_{C} \cdot \sqrt{\frac{2 \cdot k}{k+1}\left(\frac{2}{k+1}\right)^{\frac{2}{k-1}}}},\left[\mathrm{M}^{2}\right]
$$

где $T_{\mathrm{C}}-$ температура сжатого газа перед соплом, [K]; $P_{\mathrm{C}}-$ давление сжатого газа, [Па]; $R^{*}=\frac{R_{0}}{M}-$ газовая постоянная рабочего тела, [Дж/(кг К)]; $R_{0}=8314$ [Дж/(кмоль К)] - универсальная газовая постоянная; $M$ - молекулярная масса, [кг/кмоль], $G_{\mathrm{C}}-$ массовый расход сжатого потока, [кг/ч].

Присутствие в формуле (7) массового расхода затрудняет ее использование в инженерных расчетах. Более простым и удобным представляется вариант соотношения, в котором расход входящего потока представлен в виде $\mathrm{m}^{3} /$ час. Приведем $V_{\mathrm{C}}$ к нормальным условиям:

$$
V_{\mathrm{C}}=3600 \cdot \frac{G_{\mathrm{C}}}{\rho_{0}}=3600 \cdot G_{\mathrm{C}} \cdot \frac{R^{*} \cdot T_{0}}{P_{0}},
$$

где $P_{0}=0,1013$ [MПа] и $T_{0}=293$ [К] - параметры, характеризующие принятые нормальные условия; $G_{\mathrm{C}}-$ массовый расход сжатого газа, [кг/с].

При давлении холодного потока $P_{\mathrm{X}}$, близком к атмосферному $P_{0}$, будут справедливы соотношения:

$$
\begin{gathered}
\varepsilon=\frac{P_{C}}{P_{X}} \approx \frac{P_{C}}{P_{0}} ; \\
F_{\mathrm{C}}=\frac{0,95 \cdot V_{\mathrm{C}} \cdot \sqrt{T_{\mathrm{C}}}}{\varepsilon \cdot \sqrt{R^{*} \cdot \frac{2 \cdot k}{k+1}\left(\frac{2}{k+1}\right)^{\frac{2}{k-1}}},\left[\mathrm{MM}^{2}\right]} \\
F_{\mathrm{C}}=\frac{0,0105 \cdot V_{\mathrm{C}} \cdot \sqrt{T_{\mathrm{C}}}}{\varepsilon \cdot \sqrt{\frac{2 \cdot k}{M \cdot(k+1)}\left(\frac{2}{k+1}\right)^{\frac{2}{k-1}}},\left[\mathrm{MM}^{2}\right]}
\end{gathered}
$$

где $V_{\mathrm{C}}$ - объемный расход сжатого газа, [н.м ${ }^{3} /$ час]; $T_{\mathrm{C}}-$ температура газа перед соплом, [K]; $R^{*}$ - газовая постоянная, [Дж/ (кг К)]; $k$ - показатель адиабаты; $M$ - молекулярная масса [кмоль/кг].

Вычисление критического сечения сопла для заданного расхода газа по формулам (7) или (10) - (11), начальных параметров и степени расширения является первым шагом по созданию вихревой трубы (рис. 3). Далее, из формулы (5) определяется начальный диаметр камеры энергоразделения:

$$
D=\sqrt{\frac{4}{\varepsilon} \cdot \frac{F_{\mathrm{C}}}{\sigma}},[\mathrm{M}]
$$

где $F_{\mathrm{C}}$ - площадь проходного сечения сопла, [м], $\sigma$ относительное сечение сопла, $\varepsilon$ - отношение давлений, [Па/Па].

При повышенных отношениях давлений $(\varepsilon>8)$ оптимальное значение $\sigma$ приближается к нижнему пределу $(0,085)$. Для низконапорных вихревых труб $(\varepsilon<2,5)$ $\sigma$ стремится 0,1 .

Рекомендуемая длина камеры энергоразделения $L_{\Sigma}=9 \cdot d_{\mathrm{T}}$. В зависимости от доли холодного потока $\mu$ оптимальный диаметр диафрагмы $d$ изменяется. Наибольшие значения эффекта охлаждения $\Delta T_{\mathrm{X}}=\left(T_{\mathrm{C}}-\right.$ $\left.\mathrm{T}_{\mathrm{X}}\right)\left.\right|_{\max }$ достигаются при $\mu=0,2 \ldots 0,3$. При этом диаметр диафрагмы будет минимальным $d=0,42 D$. В режиме максимальной холодопроизводительности $\left.\left(G_{\mathrm{X}} \cdot \Delta T_{\mathrm{X}}\right)\right|_{\text {мАХ }}$ при $\mu=0,6 \ldots 0,7$. диафрагмы должен быть увеличен до $d=0,57 D$. Для неадиабатных вихревых труб с охлаждаемыми камерами энергоразделения $\mu=1,0$, рекомендуемый размер диафрагмы составляет $d=0,65 \cdot D$. Зависимость диаметров вихревой камеры и диафрагмы выражается соотношением:

$$
d=D \cdot(0,350+0,313 \cdot \mu),[\mathrm{M}] .
$$

где $D$ - начальный диаметр вихревой трубы, [м]; $\mu-$ доля холодного потока;

Охлажденный газ, выходящий из вихревой трубы через отверстие диафрагмы, должен иметь минимальную кинетическую энергию. Торможение вращающегося холодного потока, сопровождаемое восстановления давления, происходит в коническом диффузоре. Для 
уменьшения гидравлического сопротивления осевая протяженность цилиндрического участка диафрагмы выполняется минимальной, а расширяющийся канал не

должен содержать ступенчатых переходов и других местных сопротивлений.

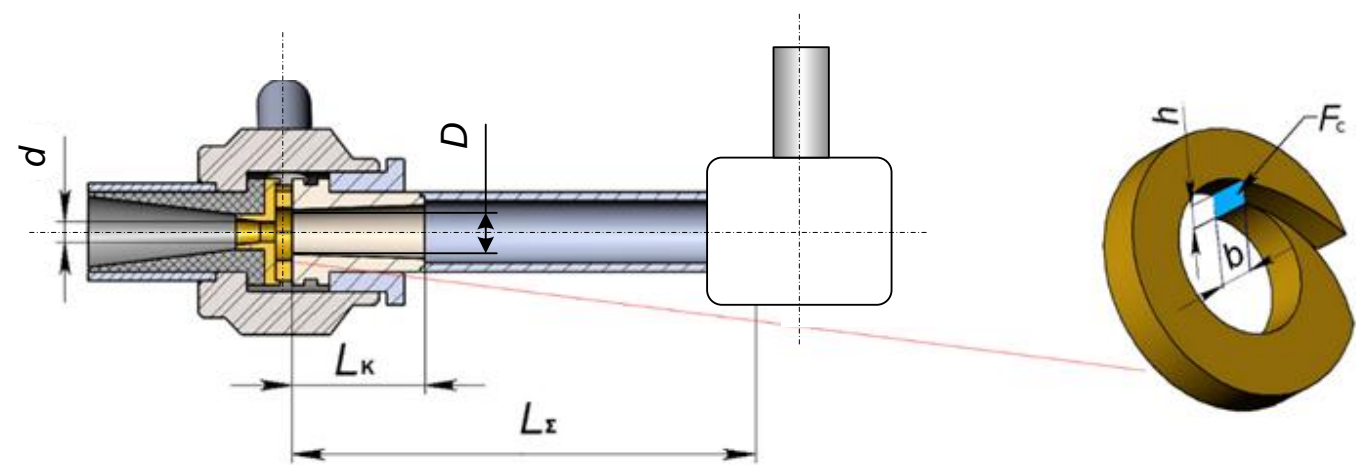

$D$ - начальный диаметр вихревой трубы, [м]; $d$ - диаметр диафрагмы, $[\mathrm{M}] ; F_{\mathrm{C}}-$ площадь сечения соплового ввода, $\left[\mathrm{M}^{2}\right] ; b$ и $h$ - ширина и высота соплового ввода, [м]; $L_{\Sigma}-$ длина вихревой трубы, $[\mathrm{M}] ; L_{\mathrm{K}}-$ длина начального конического участка, [м];

Рисунок 3 - Устройство маломасштабной вихревой трубы

\section{3 Особенности низкотемпературных вихревых устройств}

Криогенные газодинамические охладители, используемые в технологиях получения редких газов, являются маломасштабными обладают малыми размерами [9, 10]. Это условие предопределяется ограниченными расходными характеристиками установок и относи- тельно высокими давлениями на входе в сопловой ввод. На рисунке 4 приведены зависимости основных размеров вихревых аппаратов в соответствии с формулой (11) для различных газов с объемным расходом сжатого потока $V_{\mathrm{C}}=40\left[\mathrm{H} \mathrm{м}^{3} / \mathrm{\varphi}\right]$ и температурой $T_{\mathrm{C}}=78[\mathrm{~K}]$. Как следует из графиков, диаметры вихревых труб для данных условий работы находятся в интервале от 2 до 6 мм.
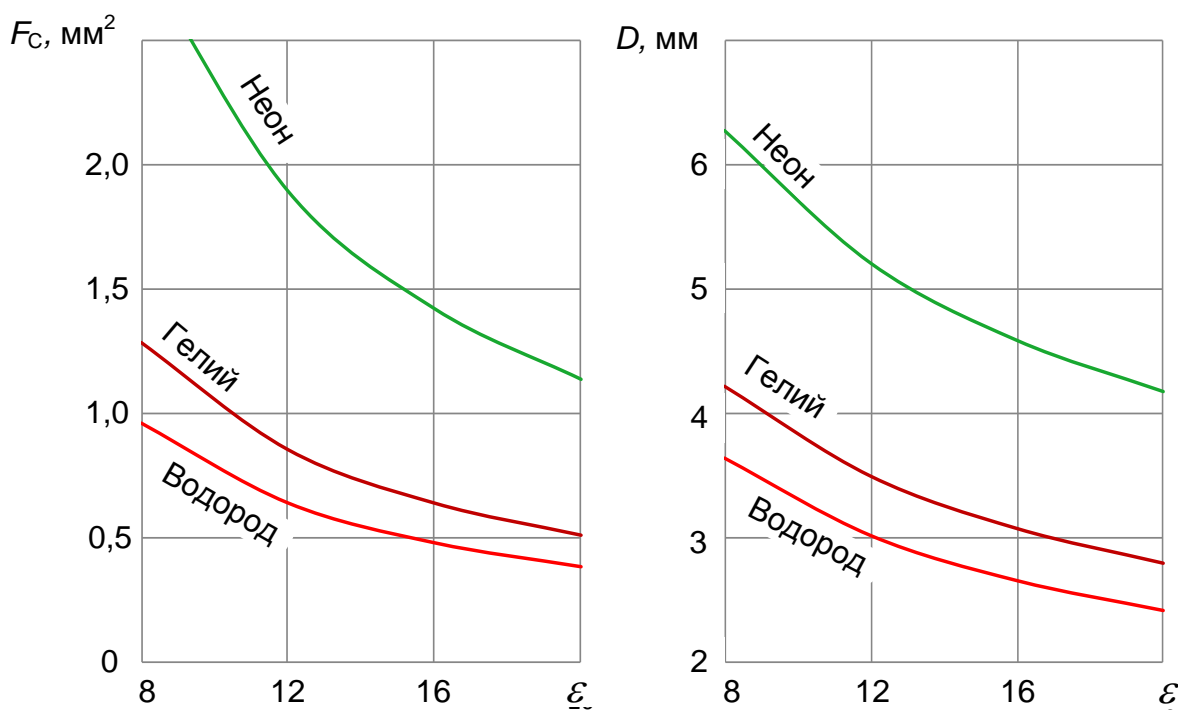

Рисунок 4. Зависимость площади критического сечения соплового ввода $F_{\mathrm{C}}$ и диаметра вихревой трубы $D$ от отношения давлений $\varepsilon$

Конструктивное исполнение маломасштабных вихревых труб (рис. 3) обычно отличается от высокорасходных аппаратов (рис. 1). Функции крестовины (поз. 4, рис. 1) во многих устройствах выполняет угловой выпуск горячего потока. Регулятор расхода горячего потока (поз. 5, рис. 1) выполняется в виде отдельного узла и может быть установлен на значительном удале- нии от вихревой трубы. В ряде криогенных установок его включают на выходе из рекуперативного теплообменника.

Из-за относительно низкого адиабатного КПД для обеспечения работы вихревых труб зачастую используются располагаемые технологические перепады давлений. Этим нивелируется основной недостаток безма- 
шинных охладителей - низкая эффективность, поскольку затраты на компримирование не требуются. В то же время такое решение диктует необходимость согласования расходных характеристик криогенераторов с параметрами существующих установок (рис. 5). Как следует из формул $(7,10,11)$ изменение условий эксплуатации $\left(P_{\mathrm{C}}, T_{\mathrm{C}}\right)$ приводит к необходимости коррек- ции $F_{\mathrm{C}}$ и связанных с ним оптимальных геометрических характеристик. Дополнительным «каналом влияния» на размеры проточной части охладителя является природа газа (в большинстве случаев - состав смеси), так как в соотношения для расчета $F_{\mathrm{C}}$ входят показатель адиабаты $k$ и молекулярная масса $M$ рабочего тела.

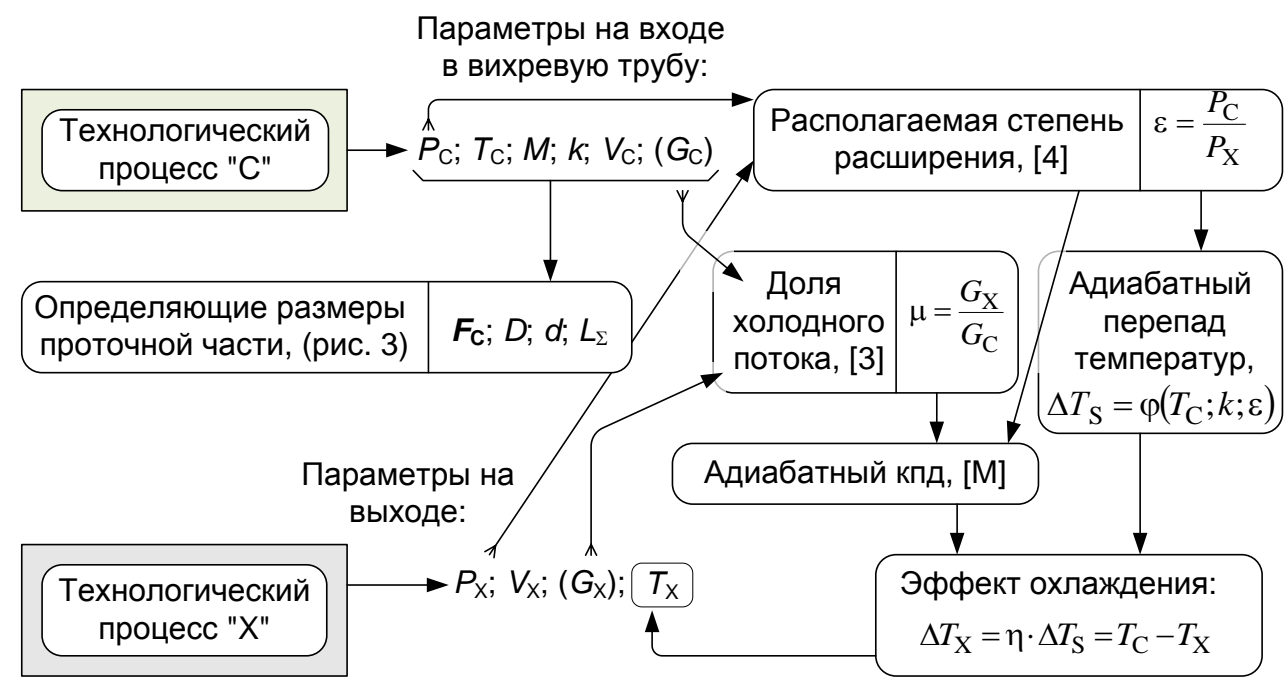

Рисунок 5. Согласование конструктивных и эксплуатационных факторов газодинамического аппарата, использующего располагаемый перепад давлений

Для согласования характеристик криогенной установки и газодинамического охладителя рекомендуются несколько приемов способов:

1) регулирование условий технологического процесса «С» для обеспечения оптимального режима работы криогенератора;

2) плавное изменение геометрических размеров соплового аппарата в процессе работы.

3) дискретное изменение расхода (за счет коррекции изменения сечения сопла) путем использования сменных деталей проточной части (рис. 3);

4) дискретное изменение расхода путем параллельного включения в схему нескольких вихревых труб;

Первый из вариантов регулирования имеет ограниченное применение, так как вмешательство в режим работы основной установки не всегда допустимо и может отрицательно сказаться на качественных и экономических показателях производства. Второй прием лишен этого недостатка, но внедрить его можно только в крупномасштабных установках или волновых криогенераторах [7].

Третий метод регулирования сечения проточной части связан с необходимостью замены сопла, вынужденно сопровождается отогревом аппарата и прерыванием процесса. Его можно практиковать крайне редко, например, в период плановых остановок. Предпочтительным способом коррекции расхода криогенератора является включение нескольких вихревых аппаратов.

Как было показано выше, переход к криогенным сферам применения практически всегда сопровождается миниатюризацией аппаратов. Известно, что умень- шение размеров газодинамических охладителей приводит к снижению их эффективности. Если для вихревой трубы с большим диаметром $D_{0}$ характерна температура холодного потока $T_{\mathrm{X} 0}$, то для меньшей вихревой трубы $D<D_{0}$ температура холодного потока окажется выше $T_{\mathrm{X}}>T_{\mathrm{X} 0}$. Эта закономерность выражается соотношением:

$$
T_{\mathrm{X}}-T_{\mathrm{X} 0}=T_{\mathrm{C}} \cdot m \cdot\left(D_{0}-D\right) \cdot\left(1-\varepsilon^{\frac{1-k}{k}}\right)
$$

где $\varepsilon$-отношение давлений, $k$-показатель адиабаты; $T_{\mathrm{C}}-$ начальная температура газа, [К]; $m$ - безразмерный эмпирический коэффициент.

В интервале $D=0,04 \ldots 0,01$ м коэффициент влияния масштаба равен $m=0,005$. При переходе к малым вихревым камерам $D=\rightarrow 4$ мм величина уменьшается до $m=0,008$. Область диаметров $D<3$ мм практически не изучена даже для «высокотемпературных» вихревых аппаратов. Создание и исследование подобных криогенных устройств сопряжено с рядом конструктивных и эксплуатационных препятствий. Возрастают требования к точности станочного оборудования, особенно при изготовлении сопловой улитки. Для снижения влияния пограничных эффектов требуется обеспечить минимальную шероховатость поверхностей проточной части. Следует учитывать влияние теплоперетоков. Для этого необходимо уменьшить сечение элементов, контактирующих с охлажденным газом и применять менее теплопроводящие материалы. 
Располагаемые перепады давлений во многих криогенных установках значительно превышают оптимальные степени расширения вихревых устройств, для которых обычно $\varepsilon<2 \cdot \varepsilon_{C}$ (3). Для повышения эффективности газодинамических охладителей практикуют их ступенчатое включение. При этом предпочтительное отношение давлений в отдельных ступенях выражается соотношением:

$$
\varepsilon_{\mathrm{i}}=\sqrt[n]{\varepsilon_{\Sigma}}
$$

где $\varepsilon_{\Sigma}$ - располагаемое отношение давлений ступенчатого охладителя; $n$-количество ступеней; $\varepsilon_{\mathrm{i}}-$ отношение давлений в отдельной ступени.
Для охлаждаемых вихревых труб $(\mu=1)$ по мере снижения давления, в соответствии с (7), сечение сопел и диаметры вихревых труб возрастают. Поэтому на эффективности второй и последующих ступеней будет положительно сказываться действие масштаба (14). Наряду с этим, в каскаде адиабатных вихревых труб расход $G_{\mathrm{Ci}}$ в каждой ступени будет падать из-за выпуска части газа в виде горячего потока $G_{\Gamma(\mathrm{i}-1)}$. Под влиянием названных взаимно противоположных факторов диаметры ступеней могут как уменьшаться, так и возрастать (рис. 6). В принципе, подбирая для каждой ступени $\varepsilon_{\mathrm{i}}$ и $\mu_{\mathrm{i}}$ можно сформировать каскад в виде унифицированных (однотипных) адиабатных вихревых труб.
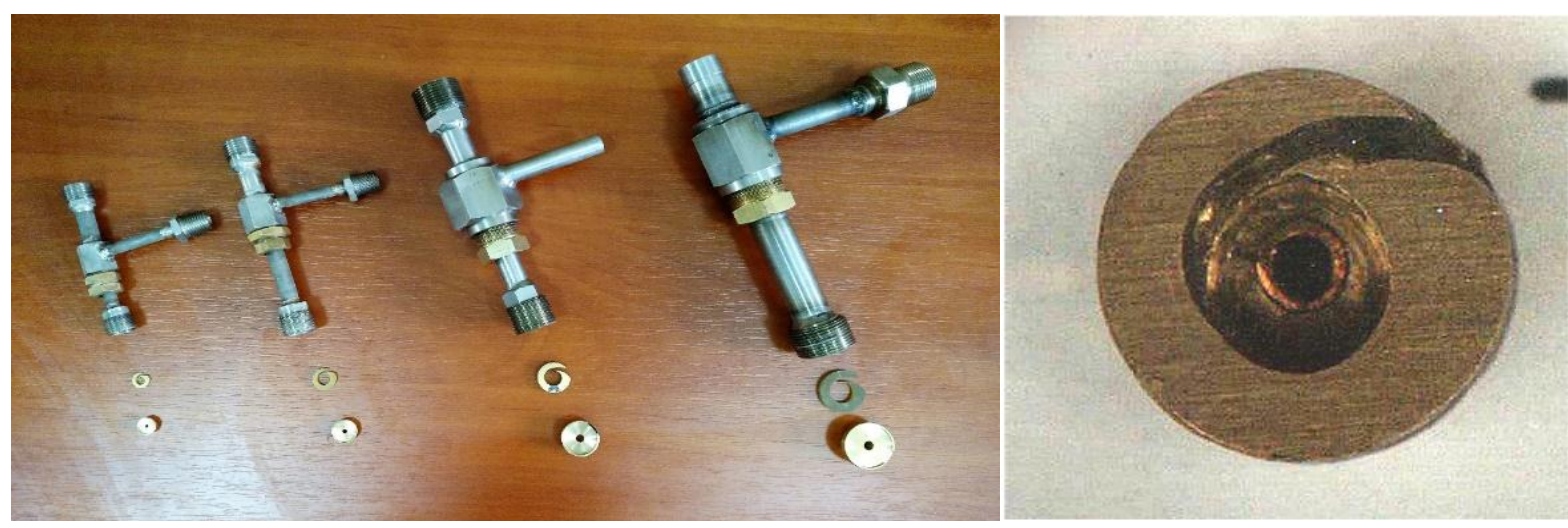

Рисунок 5 - Вихревые трубы диаметром D = 3...10 мм для четырехступенчатого каскадного охладителя и их детали

\section{Заключение}

Вихревые трубы уступают по эффективности расширительным машинам. В установках для получения инертных компонентов воздуха имеются технологические перепады давления, которые допускают включение безмашинных аппаратов без затрат энергии на компримирование питающего газа. Такое решение повышает конкурентоспособность вихревых устройств, обладающих рядом конструктивных и эксплуатационных достоинств по сравнению с детандерами. Для обеспечения оптимальных перепадов давления рекомендуется каскадное включение вихревых труб. Согласование расходных характеристик охладителей и криогенных сепараторов обеспечивается параллельным включением нескольких газодинамических устройств.

\section{Литература}

[1] Мартыновский В.С., Алексеев В.П. Исследование эффекта вихревого температурного разделения газов и паров. - ЖТФ, 1956, т.26, вып. 10, с. 2303 - 2315.

[2] Азаров А.И., Вихревые трубы в промышленности. Санкт-Перербург.: Лема, 2010, 172 с.

[3] Азаров А.И., Симоненко Ю.М. Трехступенчатый вихревой кондиционер для душирования рабочего ме- ста. Холодильная техника и технология. - 1981. - Вып. $32-$ С. 6-10

[4] Азаров А.И., Симоненко Ю.М., Муратов С.О. Влияние параметров охлаждающего потока на эффективность оребренных вихревых труб. Холодильная техника и технология. -1985. - Вып. 40. - С. 7-9.

[5] Суслов А.Д., Иванов С.В., Мурашкин А.В., Чижиков Ю.В. Buхревые annapambl. Москва, Изд-во Машиностроение, 1985, $256 \mathrm{c.}$

[6] Меркулов А.П. Вихревой эффект и его применение в технике. Москва, Изд-во Энергия, 1977, 343 с.

[7] Кириллин В. А., Сычев В. В., Шейндлин А. Е. Техническая термодинамика. Москва, Изд-во Энергия, 1974, 447 c.

[8] Архаров А.М. Волновые криогенераторы и их применение для повышения эффективности криогенных установок / А.М. Архаров, В.Л. Бондаренко, В.И. Липа // Труды МВТУ. - Вып. 430. - 1984. - С. 3745.

[9] Bondarenko V.L., Arkharov A.M., Symonenko Iu.M. Wave Cryogenerators Applied in Technologies of Rare Gas Separation. The 22nd International Congress of Refrigeration, China, Beijing, 2007, ICR-A2-132.

[10] Бондаренко В. Л., Лосяков Н. П., Симоненко Ю. М. Промышленное применение вихревых и пульсационных охладителей в технологиях извлечения редких газов. Технические газы, 2009, №5, с. 50-58. 


\title{
Application of vortex gas-dynamic coolers in the rare gases extracting technologies
}

\author{
V. L. Bondarenko ${ }^{I}$ Iu. M. Symonenko ${ }^{2}$, L. N. Tsvetkovskaya ${ }^{3}$, D. P. Tyshko ${ }^{4 \bowtie}$ \\ 1. Bauman Moscow State Technical University, ul. Baumanskaya 2-ya, 5, Moscow, 105005, Russia \\ 2, 3. Odessa National Academy of Food Technologies, Kanatna Street, 112, Odessa, 65039, Ukraine \\ 4. Cryoin Engineering, LTD. 1-A Mytna square, Odessa, 65026, Ukraine \\ ORCID: ${ }^{1}$ http://orcid.org/0000-0003-1562-7255; ${ }^{2}$ http://orcid.org/0000-0002-7827-0591; \\ ${ }^{3}$ https://orcid.org/0000-0002-3956-583X; ${ }^{4}$ http://orcid.org/0000-0002-9598-6292; \\ $\triangle$ e-mail: dtishko@cryoin.com
}

Vortex tubes are inferior it to expander efficiency, but they have a number of incontestable advantages, such as compactness, high reliability, multifunctionality. Despite these advantages, there are several examples of vortex tubes effective use in cryogenics. The problems accompanying to the creation of vortex coolers, designed for neon and heliu, producing units were discussed. The transition to low temperatures level is always accompanied with gas-dynamic devices miniaturization. At the same time? Most of the recommendations for vortex devices design refers to high-flow facilities that are powered by air with ambient temperatures. For this reason, known geometric relations aren't useful for vortex units with small diameters of the energy separation chamber $(D)$. The scale factor effect in the diameter interval less than 10 mm has been studied experimentally. The advantages of low-temperature vortex tubes stepwise switching in the schemes of rare gas separators units were shown. The use of a technological pressure difference for feeding vortex devices was justified. At the same time, the work of gas-dynamic coolers does not require additional energy costs, since they trigger the pressure of compressed gas, which previously was uselessly reduced.

Key words: Cryogenic technics; Rare gases; Vortex tube; Scale factor.

\section{References}

1 Мартыновский В.С., Алексеев В.П. Исследование эффекта вихревого температурного разделения газов и паров. - ЖТФ, 1956, т.26, вып. 10, с. 2303 - 2315.

2 Азаров А.И., Вихревые трубы в промышленности. Санкт-Перербург.: Лема, 2010, 172 с.

3 Азаров А.И., Симоненко Ю.М. Трехступенчатый вихревой кондиционер для душирования рабочего места. Холодильная техника и технология. - 1981. - Вып. 32 - С. 6-10.

4 Азаров А.И., Симоненко Ю.М., Муратов С.О. Влияние параметров охлаждающего потока на эффективность оребренных вихревых труб. Холодильная техника и технология. -1985. - Вып. 40. - С. 7-9.

5 Суслов А.Д., Иванов С.В., Мурашкин А.В., Чижиков Ю.В. Buxpeвble annapambl. Москва, Изд-во Машиностроение, 1985, 256 с.

6 Меркулов А.П. Вихревой эффект и его применение 6 технике. Москва, Изд-во Энергия, 1977, 343 с.
7 Кириллин В. А., Сычев В. В., Шейндлин А. Е. Техническая термодинамика. Москва, Изд-во Энергия, 1974, 447 c.

8 Архаров А.М. Волновые криогенераторы и их применение для повышения эффективности криогенных установок / А.М. Архаров, В.Л. Бондаренко, В.И. Липа // Труды МВТУ. - Вып. 430. - 1984. C. 37-45.

9 Bondarenko V.L., Arkharov A.M., Symonenko Iu.M. Wave Cryogenerators Applied in Technologies of Rare Gas Separation. The 22nd International Congress of Refrigeration, China, Beijing, 2007, ICR-A2-132.

10 Бондаренко В. Л., Лосяков Н. П., Симоненко Ю. М. Промышленное применение вихревых и пульсационных охладителей в технологиях извлечения редких газов. Технические газы, 2009, №5, с. 50-58.

Received 04 March 2018 Approved 24 April 2018 Available in Internet 30 June 2018 